\title{
Article \\ Healthcare Voucher Scheme for Screening of Cardiovascular Risk Factors: A Population-Based Study
}

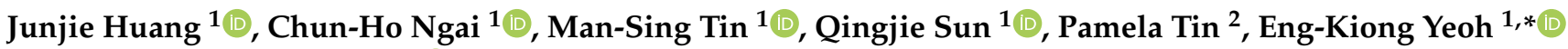 \\ and Martin C. S. Wong $1,3,4, *$ (i)
}

1 The Jockey Club School of Public Health and Primary Care, Faculty of Medicine, Chinese University of Hong Kong, Hong Kong SAR 999077, China; junjie_huang@link.cuhk.edu.hk (J.H.); alfonse.ngai@gmail.com (C.-H.N.); mstin0911@gmail.com (M.-S.T.); stellarsun@cuhk.edu.hk (Q.S.)

2 Department of Healthcare and Social Development Research, Our Hong Kong Foundation, Hong Kong SAR 999077, China; pamela.tin@ourhkfoundation.org.hk

3 School of Public Health, The Chinese Academy of Medical Sciences and Peking Union Medical College, Beijing 100050, China

4 Department of Global Health, School of Public Health, Peking University, Beijing 100871, China

* Correspondence: yeoh_ek@cuhk.edu.hk (E.-K.Y.); wong_martin@cuhk.edu.hk (M.C.S.W.)

Citation: Huang, J.; Ngai, C.-H.; Tin, M.-S.; Sun, Q.; Tin, P.; Yeoh, E.-K.; Wong, M.C.S. Healthcare Voucher Scheme for Screening of Cardiovascular Risk Factors: A Population-Based Study. Int. J. Environ. Res. Public Health 2021, 18, 10844. https://doi.org/10.3390/ ijerph182010844

Academic Editors: Izabella Lecka, Sally Brailsford, Józef Haczyński and Remigiusz Kozlowski

Received: 17 September 2021

Accepted: 11 October 2021

Published: 15 October 2021

Publisher's Note: MDPI stays neutral with regard to jurisdictional claims in published maps and institutional affiliations.

Copyright: (c) 2021 by the authors. Licensee MDPI, Basel, Switzerland. This article is an open access article distributed under the terms and conditions of the Creative Commons Attribution (CC BY) license (https:// creativecommons.org/licenses/by/ $4.0 /)$.

\begin{abstract}
The present study aimed to evaluate the factors associated with unwillingness to join a healthcare voucher scheme for screening of cardiovascular risk factors in a Chinese population. We conducted a telephone survey by random selection of 1200 subjects who were aged 45 years or above in Hong Kong. We collected data on their attitude, perception, and perceived feasibility of a healthcare voucher scheme. The overall rates of having received at least one type, two types, and all three types of screening tests are $81.1 \%, 80.7 \%$, and $79.3 \%$, respectively. Younger individuals $(\mathrm{aOR}=0.338, p=0.004)$, those of a higher educational level $(\mathrm{aOR}=1.825, p=0.006)$, being employed $(\mathrm{aOR}=3.030, p=0.037)$, and lower perception of screening as beneficial ( $\mathrm{aOR}=0.495, p<0.001)$ were significantly associated with no regular screening for at least one medical condition. The overall rate of willingness to join the voucher scheme (among those aged $\geq 45)$ is $83.7 \%$. Male sex $(\mathrm{aOR}=2.049$, $p=0.010)$ and absence of family history of cardiovascular disease (aOR $=0.362, p=0.002)$ are independent predictors of unwillingness to join. Our findings highlighted the significance of sex and family history on screening of cardiovascular factors. These constructs and independent predictors identified provide evidence-based formulation and implementation targeted screening strategies that enhance the screening rate of the three cardiovascular risk factors.
\end{abstract}

Keywords: voucher; screening; cardiovascular diseases; population; health policy

\section{Introduction}

Of the 40 million global deaths caused by non-communicable diseases (NCDs) in 2016, an estimated 32 million NCD-related deaths were attributable to diabetes, cardiovascular diseases, chronic respiratory diseases, and cancers [1]. Concurrently, a rising prevalence of multiple chronic conditions (MCC), shown to impose significant burdens on healthcare costs and utilisation, has been reported by epidemiological studies across the world [2] Population ageing, improved diagnosis, and detection of diseases, changes to sedentary lifestyles, and increasing consumption of high-calorie diets are among the key contributors to this rising prevalence [3].

There are usually no signs or symptoms associated with high blood pressure, diabetes, or lipid disorders in the early stage, yet these disorders are recognised as important risk factors for cardiovascular diseases (CVD), stroke, and mortality [4]. Specifically, the lack of early detection contributes to late diagnosis of these chronic diseases, leading to the development of more severe complications [5]. To tackle these chronic conditions, early detection by regular screening has been proposed as an effective measure for earlier diagnosis of 
hypertension, diabetes, and hyperlipidaemia, which facilitates timely treatment and saves healthcare costs [6]. Screening is also essential for better long-term management, lowering avoidable hospital admissions, and alleviating the demand on healthcare utilization. All these favourable outcomes can eventually lead to more efficient health services.

The rising prevalence of hypertension, diabetes, and lipid disorders in younger age groups and the high proportion of undiagnosed individuals necessitate preventive care and early detection. The major onset of these three chronic diseases is commonly found at an age of 45 years [7], and the risk for people diagnosed with at least one chronic disease at this age is six times higher than that for younger people in Hong Kong [8]. Therefore, it is important for promote screening in this older population in Hong Kong. A recent simulation study in Thailand suggested that undiagnosed diabetes was most commonly found among those aged under 39 years, and that mortality of those with undiagnosed diabetes was ten-fold higher than that of those with diagnosed diabetes, supporting the importance of early detection and intervention [9]. Population statistics indicate the necessity for screening programmes to be targeted at 'younger' age groups to facilitate early detection and intervention, an implication consistent with study findings. Complementary studies to understand the key facilitators or barriers in health seeking behavior should also be considered among people of different age groups [10].

In Hong Kong, the increasing prevalence of NCDs poses significant challenges to our overburdened health system. Specifically, according to updated statistics from the Department of Health of the Hong Kong government, diseases associated with diabetes, lipid disorders, and heart diseases were among the top 10 leading causes of death in 2019 [11]. Notably, these three conditions are among the most commonly diagnosed chronic diseases in Hong Kong, and the co-occurrence of these diseases is widely observed. The 2014/15 Department of Health (DH) Population Health Survey showed an increase in prevalence of hypertension across age groups, even in a younger age group (35-44). Approximately $15.2 \%$ of individuals aged 35-44 were found to be hypertensive compared to the notable $26.7 \%$ among those aged $45-54$. Importantly, as many as two thirds of all surveyed individuals had not previously been diagnosed as hypertensive [12]. Similar patterns have been observed for diabetes and lipid disorders. Diabetes continues to be a major cause of morbidity and mortality in Hong Kong, accounting for $0.9 \%$ of all deaths in 2017 [13]. The estimated prevalence of diabetes stands at approximately $10 \%$ of the local adult population [13] and 7.3\% among those aged 45-54, of which $36.4 \%$ have not been previously diagnosed. A study by Quan et al. (2017) also demonstrated a rising prevalence of diabetes in Hong Kong, accounting for a significant rise in morbidity, premature mortality, and healthcare expenditure from 2006 to 2014 [14]. Additionally, the overall prevalence of pre-diabetes is increasing [15], a condition that could progress and lead to a diagnosis of diabetes if not detected and managed in a timely manner. Separately, based on the 2014 to 2015 Population Health Survey by the DH, an estimated $49.5 \%$ of the Hong Kong population aged 15 to 84 years had hyperlipidaemia, referring to elevated blood lipid levels and indicated by hypercholesterolemia. Yet, $70.2 \%$ of cases were undiagnosed before the administration of the health survey [7].

To address the widespread issues of undiagnosed chronic illness and the potential harm from absence of timely diagnosis internationally, screening for CVD-related chronic diseases have shifted to the forefront of governments' efforts, resulting in adoption of screening programmes supported by clinical guidelines globally [16-19]. In the UK, people aged 40-74 receive complimentary health checks from the National Health Service (NHS), including measurement of blood pressure, glucose levels, plasma cholesterol, and BMI. Besides periodic health assessment, a nationwide NHS Diabetes Prevention Programme (NHS DPP) was also launched in 2016 to screen individuals over the age of 18 who are at high risk of developing Type 2 diabetes. This programme was a joint commitment from the NHS, Public Health England, and Diabetes UK. Although the programme is still undergoing, and the final evaluation report has not been released, one of its progress reports published recorded that over 40,000 people with non-diabetic hyperglycaemia conditions 
were referred to the programme for intervention [20]. In a separate example, an expert panel of diabetes expertise stakeholders recently proposed a new screening approach in Australia [21]. The Pharmacy Diabetes Screening Trial was established to provide community screening across regional remote areas and metropolitan of Australia, with thorough research to support the feasibility and value of pharmacy as a component of population screening efforts. Pharmacists would assess a patient's risk of developing diabetes and refer the patient to their general practitioners for follow-up. The trial had successfully screened out more than 14,000 patients aged between 35 to 75 years and detected over 100 undiagnosed type 2 diabetes patients according to its preliminary results. Meanwhile, in the Asia Pacific region, the Ministry of Health in Singapore launched a national screening programme, named "Screen for Life (SFL)" in 2017. This SFL programme subsidizes citizens from age 25 and above to screen for hypertension, hyperlipidemia, diabetes, cervical cancer, and colorectal cancer, which helped screening for over 100,000 individuals with $40 \%$ identified as having potential chronic illness risk [22,23].

Rooting from the economic theories of supply and demand, the use of vouchers as a demand side mechanism increases utilisation of aims to health services for individuals with the need. Such mechanism enables the government to distribute resources in a more efficient manner by focusing on the targeted group, and it has been adopted as one of the effective means to promote health-seeking behaviour [24] This has been shown to be effective in overcoming financial, social and psychological barriers to facilitate the uptake of underutilised services prescribed by the scheme [25]. Additionally, the grounds were to encourage consumption of services, hence shifting the demand curve to the right and offering maximum positive externalities such as lowering long-term medical cost and increase in service quality to the society [26]. In other words, covering the majority of the populations and enrolling healthcare providers to see all voucher clients without 'cherry picking' will stimulate both supply and demand for need services which are the aim of the voucher programmes. Learning from international experiences, most voucher schemes implemented in low- or middle-income countries targeting specific health services (i.e., mental health services, reproductive health services) had been effective in promoting the utilisation and uptake rates of screening programmes [25,27-31]. Thus, building on the current healthcare voucher scheme, we envision the proposed population-based chronic disease screening voucher and disease management programme to be used by the Government as an instrument to not only promote early detection and disease management but also, importantly, to further promote well-coordinated public-private partnerships. This could shift the care burden from the public to private sector and thus alleviate the service demands of the overburdened public healthcare system [32].

The Elderly Health Care Voucher Scheme (EHCVS) in Hong Kong was launched as a pilot on 1 January 2009 and was converted into a standard recurrent programme in 2014 [33]. Currently, the scheme offers HKD 2000 to the resident population aged 65 and above every year, and each individual can accumulate unused entitlements up to HKD 8000. The scheme aims to incentivise the monetary incentives utilisation of primary care services in the private sector, allowing older people to seek healthcare from 10 categories of health professionals including western trained doctors, traditional Chinese medicine practitioners, nurse, physiotherapists, radiographers, optometrists, and dentists for both curative and preventive care [32,33]. The establishment of the EHCVS aims to enable private healthcare practitioners supplement the services in the public sector, thereby lowering the demand on the public sector $[9,34]$. However, over $90 \%$ of the voucher users reported using the voucher for acute care only, and less than $20 \%$ of the EHCVS participants used the vouchers for preventive care [32] when the voucher was first piloted. Studies have found a lack of confidence in the private healthcare services and the inadequacy of the healthcare voucher to cover all the consultation cost, which led to the current scheme, which has been enhanced and entitlements substantiality increased. Hence, the need to pay out-of-pocket expenses was a major reason for its low utilization level [32,35]. In light of this, building on the lessons learned from the EHCVS that is already in place, 
there is an opportunity for government to consider implementing a population-based chronic disease screening and management voucher programme. This not only promotes prevention through early detection of targeted chronic illnesses, but also supports followup chronic disease management plans that should take place in the community rather than in hospitals [36].

The current study aimed to evaluate the factors associated with not joining screening of cardiovascular risk factors and the unwillingness of joining a healthcare voucher scheme for promoting such screening in the Chinese population.

\section{Materials and Methods}

\subsection{Subjects}

All subjects who (1) were aged 45 years or above; (2) could communicate in either Cantonese, Putonghua, or English (which are the three most commonly used languages in Hong Kong); and (3) resided in a Hong Kong household at the time of the study were eligible to participate in this study.

\subsection{Survey Instrument}

The questionnaire consisted of survey items in Chinese (or Putonghua or English as applicable), which collected data on subjects' attitude, perception, and perceived feasibility of the healthcare voucher scheme. Socio-demographic information, family and personal history of chronic diseases, self-perceived health status, and screening histories of chronic diseases were collected. The survey was designed based on qualitative interviews of relevant stakeholders in the proposed screening programme. Some of the constructs (attitudes, perceived benefits, and perceived health and psychological barriers) were developed based on the health belief model [37]. It was devised, pilot-tested and validated by a panel of epidemiologists, biostatisticians, physicians, and experts on healthcare systems.

The different parts of the validated survey include: (1) socio-demographic information: age, sex, educational level, marital status, employment status, and personal income; (2) family and personal history of chronic diseases, including hypertension, diabetes, and high blood cholesterol; (3) history of screening for hypertension, obesity, diabetes, and dyslipidaemia; (4) perceived benefits of chronic disease screening; and (5) perceived health or psychological barriers, including perceived lack of screening necessity, lack of screening benefits, busy working schedules, financial considerations, concerns about subsequent management of chronic diseases, and unawareness of screening venues.

\subsection{Sampling Frame and Subject Recruitment}

The sampling frame consists of all eligible subjects for the scheme. We purposively sampled an older population because of the nature of the study. Based on the sample size calculated, we used a computer randomizer to generate random numbers to select individuals for the surveys. The selection of the sample population was conducted by the Centre for Behavioural Research of the School of Public Health and Primary Care, The Chinese University of Hong Kong using simple random sampling.

One telephone number was considered one unit of randomization. Since a minority of family households had more than one fixed telephone line, all participants were asked if they have already been recruited in the survey to avoid double counting. Cell phone numbers were not included in the telephone directories for the present survey. If the target subject was not available, at least five call attempts in two different daytimes and three different evenings were given. If the target subject was available but too busy to receive the telephone interview, a mutually convenient time was scheduled to administer the survey.

According to standard methodology, only one subject was recruited from each household to avoid clustering effect within household [38]. Non-response was defined as noncompletion of the survey after five telephone attempts. Non-respondents were replaced by the next subsequent household telephone number. The interviewed subjects were briefed about the purpose of the study, assured of the confidentiality of the telephone interview, 
and requested to provide informed consent. Enquiry telephone numbers of the survey were provided to the respondents for any inquiries arising from study participation.

\subsection{Data Processing and Analysis}

All the data were entered into a software spreadsheet and analysed by the Statistical Package for Social Sciences (SPSS) version 21.0. (IBM Corp, NY, USA). A descriptive analysis of the socio-demographic data, clinical information, family history of chronic diseases, self-purchased health insurance, and the perceived adequacy of financial resource to pay healthcare expenditure was performed. The primary outcome variables included (1) not participating in screening for hypertension, diabetes, and lipid disorders; and (2) unwillingness to join the healthcare voucher scheme for hypertension, diabetes, and lipid screening. The association between each predictor variable was examined with the outcome variables by univariate analysis. Binary logistic regression models were constructed to examine the independent association between the predictors having $p \leq 0.10$ in the univariate analysis and each outcome variable, separately. All $p$ values $\leq 0.05$ in the final regression model were regarded as statistically significant.

\subsection{Sample Size Calculation}

We assumed $50 \%$ as the proportion in all the outcomes which would provide the maximum sample size. A sample size of approximately 1200 participants could achieve a precision level of 0.03 , from the formula: "precision $=1.96 \times \sqrt{ }[(p) \times(1-p) / N]$ ".

\section{Results}

\subsection{Participant Characteristics}

A total of 1200 respondents were recruited in the current study (Table 1). The majority of the individuals were aged $\geq 65$ years $(63.4 \%)$, followed by subjects aged $55-64$ years $(26.6 \%)$ and $45-54$ years $(10.0 \%)$. Most respondents were female $(69.2 \%)$ and attained primary educational level or lower $(45.3 \%)$. The majority were retired $(54.0 \%)$ or were housewives (29.8\%). Among them, 63.5\% had been using medications for chronic diseases or were attending regular medical follow-up, where most of the healthcare consultations took place in the private sector $(56.8 \%)$. Approximately $51.9 \%$ reported family history of hypertension, diabetes, lipid disorders, or stroke. The majority $(74.5 \%)$ were not covered by self-purchased health insurance. A substantial proportion of the respondents perceived their financial resource to pay healthcare expenditure as inadequate $(37.3 \%)$ and very inadequate $(12.7 \%)$.

\subsection{Factors Associated with Not Screening for Hypertension, Diabetes and Lipid Disorders}

The overall rates of having received at least one, two, and all three types of screening test were $81.1 \%, 80.7 \%$, and $79.3 \%$, respectively. From univariate analysis (Table 2), younger age (cOR for $55-64$ years: $0.550,95 \%$ C.I. $0.355,0.855, p=0.008$; cOR for $\geq 65$ years: $0.191,95 \%$ C.I. $0.125,0.293, p<0.001$ ); higher educational level (cOR for secondary and tertiary educational level $=2.725$ and 2.183, respectively); being employed (cOR for being employed $=2.033,95 \%$ C.I. $1.399,2.959, p<0.001$ ); non-recipients of comprehensive social security assistance (receipt of CSSA COR 0.360, 95\% C.I. 0.128, 1.099, $p=0.052$ ); perception of screening being beneficial (cOR 0.565, 95\% C.I. 0.411, 0.778, $p<0.001$ ); and family history without chronic diseases (cOR 0.422, 95\% C.I. 0.310, 0.573, $p<0.001$; referent: family history with chronic diseases) were significant covariates. In the multiple regression analysis, younger individuals (aOR 0.338, 95\% C.I. 0.161, 0.711, $p=0.004$; referent: subjects aged $\geq 65$ years); higher educational level (aOR for secondary and tertiary educational level $=1.825$ and 1.391 , respectively); being employed $(\mathrm{aOR}=3.030,95 \%$ C.I $1.068,8.621, p=0.037$ ); lower perception of screening as beneficial (aOR $0.495,95 \%$ C.I. $0.345,0.710, p<0.001$ ); older individuals who have a family history of chronic diseases (aOR for $\geq 65$ years by with family history $=0.284,95 \%$ C.I. $0.109,0.736, p=0.010$ ); and employed individuals with high educational level (aOR for secondary by employed $=0.270$, 
$95 \%$ C.I. $0.084,0.864, p=0.027$; aOR for tertiary by employed $=0.136,95 \%$ C.I. $0.034,0.548$, $p=0.005$ ) were significantly associated with no regular screening for at least one medical condition. The significant covariates from regression analysis for not having received at least two (Table 3) or all three types (Table 4) of screening tests were similar.

Table 1. Characteristics of the respondents.

\begin{tabular}{|c|c|c|}
\hline & $\mathbf{n}$ & $\%$ \\
\hline \multicolumn{3}{|l|}{ Age (years) } \\
\hline $45-54$ & 120 & 10.0 \\
\hline $55-64$ & 319 & 26.6 \\
\hline$\geq 65$ & 761 & 63.4 \\
\hline \multicolumn{3}{|l|}{ Gender } \\
\hline Male & 370 & 30.8 \\
\hline Female & 830 & 69.2 \\
\hline \multicolumn{3}{|l|}{ Educational level } \\
\hline Primary or below & 543 & 45.3 \\
\hline Secondary & 479 & 39.9 \\
\hline Tertiary or above & 154 & 12.8 \\
\hline Refused to answer & 24 & 2 \\
\hline \multicolumn{3}{|l|}{ Job status } \\
\hline Full-time or part-time & 164 & 13.7 \\
\hline Retired & 648 & 54.0 \\
\hline Housewife & 358 & 29.8 \\
\hline Student & 0 & 0 \\
\hline Unemployed & 22 & 1.8 \\
\hline Refused to answer & 8 & 0.7 \\
\hline \multicolumn{3}{|l|}{ Monthly personal income (HKD) } \\
\hline$<10,000$ & 20 & 1.7 \\
\hline $10,000-19,999$ & 47 & 3.9 \\
\hline $20,000-29,000$ & 33 & 2.8 \\
\hline $30,000-60,000$ & 22 & 1.8 \\
\hline$>60,000$ & 10 & 0.8 \\
\hline Unstable income & 6 & 0.5 \\
\hline Refused to answer & 26 & 2.2 \\
\hline N/A as no current job & 1036 & 86.3 \\
\hline \multicolumn{3}{|l|}{ Recipient of CSSA } \\
\hline Yes & 52 & 4.3 \\
\hline No & 1140 & 95.0 \\
\hline Refused to answer & 8 & 0.7 \\
\hline \multicolumn{3}{|l|}{$\begin{array}{l}\text { Regular follow-up or use of medication for } \\
\text { chronic diseases }\end{array}$} \\
\hline Yes & 762 & 63.5 \\
\hline No & 436 & 36.3 \\
\hline Refused to answer & 2 & 0.2 \\
\hline \multicolumn{3}{|l|}{ Healthcare consultations mainly in } \\
\hline Public sector & 274 & 22.8 \\
\hline Private sector & 682 & 56.8 \\
\hline Public or private (more or less equal) & 194 & 16.2 \\
\hline Don't know/no opinions & 38 & 3.2 \\
\hline $\begin{array}{l}\text { Others (Chinese Medicine, over-the-counter } \\
\text { drugs) }\end{array}$ & 12 & 1.0 \\
\hline
\end{tabular}


Table 1. Cont.

\begin{tabular}{|c|c|c|}
\hline & $\mathbf{n}$ & $\%$ \\
\hline \multicolumn{3}{|l|}{$\begin{array}{l}\text { Family history of hypertension, diabetes, } \\
\text { lipid disorders, or stroke }\end{array}$} \\
\hline Yes & 623 & 51.9 \\
\hline No & 492 & 41.0 \\
\hline Don't know/no opinions & 78 & 6.5 \\
\hline Refused to answer & 7 & 0.6 \\
\hline \multicolumn{3}{|l|}{ Medical insurance provided by employers } \\
\hline Yes & 87 & 7.2 \\
\hline No & 70 & 5.8 \\
\hline Not applicable (no employers) & 1031 & 85.9 \\
\hline Don't know / no opinions & 1 & 0.1 \\
\hline Refused to answer & 11 & 0.9 \\
\hline \multicolumn{3}{|l|}{ Self-purchased health insurance } \\
\hline $\begin{array}{l}\text { Yes, Voluntary Health Insurance Scheme } \\
\text { (VHIS) }\end{array}$ & 3 & 0.3 \\
\hline Yes, personal health insurance & 253 & 21.1 \\
\hline Both VHIS and personal health insurance & 9 & 0.8 \\
\hline No & 894 & 74.5 \\
\hline Don't know/no opinions & 0 & 0.0 \\
\hline Refused to answer & 41 & 3.4 \\
\hline \multicolumn{3}{|l|}{$\begin{array}{l}\text { Perceived adequacy of financial resource to } \\
\text { pay healthcare expenditure }\end{array}$} \\
\hline More than adequate & 9 & 0.8 \\
\hline Adequate & 166 & 13.8 \\
\hline Just enough & 196 & 16.3 \\
\hline Inadequate & 447 & 37.3 \\
\hline Very inadequate & 152 & 12.7 \\
\hline Don't know/no opinions & 212 & 17.7 \\
\hline Refused to answer & 18 & 1.5 \\
\hline
\end{tabular}

\subsection{Factors Associated with Unwillingness to Join the Voucher Scheme Programme for Screening}

The overall rates of willingness to join the voucher scheme (among those aged $\geq 45$ ) is $83.7 \%$. We excluded subjects who were attending regular follow-up in clinics for hypertension, diabetes, lipid disorders, or stroke. In univariate analysis of absence of willingness to join the EHCVS for preventive screening (Table 5), male individuals ( $\mathrm{COR}=2.198,95 \%$ C.I. $1.309,3.690, p=0.003)$ and those without family history of the above-mentioned chronic diseases ( $\mathrm{cOR}=0.341,95 \%$ C.I. $0.182,0.638, p=0.001$; referent: with family history) were significantly more likely to express unwillingness to join the screening programme. Being male $(\mathrm{aOR}=2.049,95 \%$ C.I. $1.183,3.546, p=0.010)$ and the absence of family history $(\mathrm{aOR}=0.362,95 \%$ C.I. $0.192,0.680, p=0.002$; referent: with family history) remained to be the significant predictors of unwillingness to receive screening for conditions in the multivariate regression model (Table 5).

To further analyse the results by gender (Table 6), we found fewer males were willing to participate in the voucher scheme compared with females (75.6\% vs. $87.2 \%, p=0.003)$. Male subjects were more likely to be employed ( $42.7 \%$ vs. $15.2 \%, p<0.001)$, of high income $(34.2 \%$ vs. $17.5 \%, p<0.001)$, without family history of cardiovascular diseases $(67.2 \%$ vs. $57.3 \%, p=0.039)$, and with health insurance ( $48.4 \%$ vs. $37.6 \%, p=0.039)$. 
Table 2. Factors associated with not screening for at least one factor.

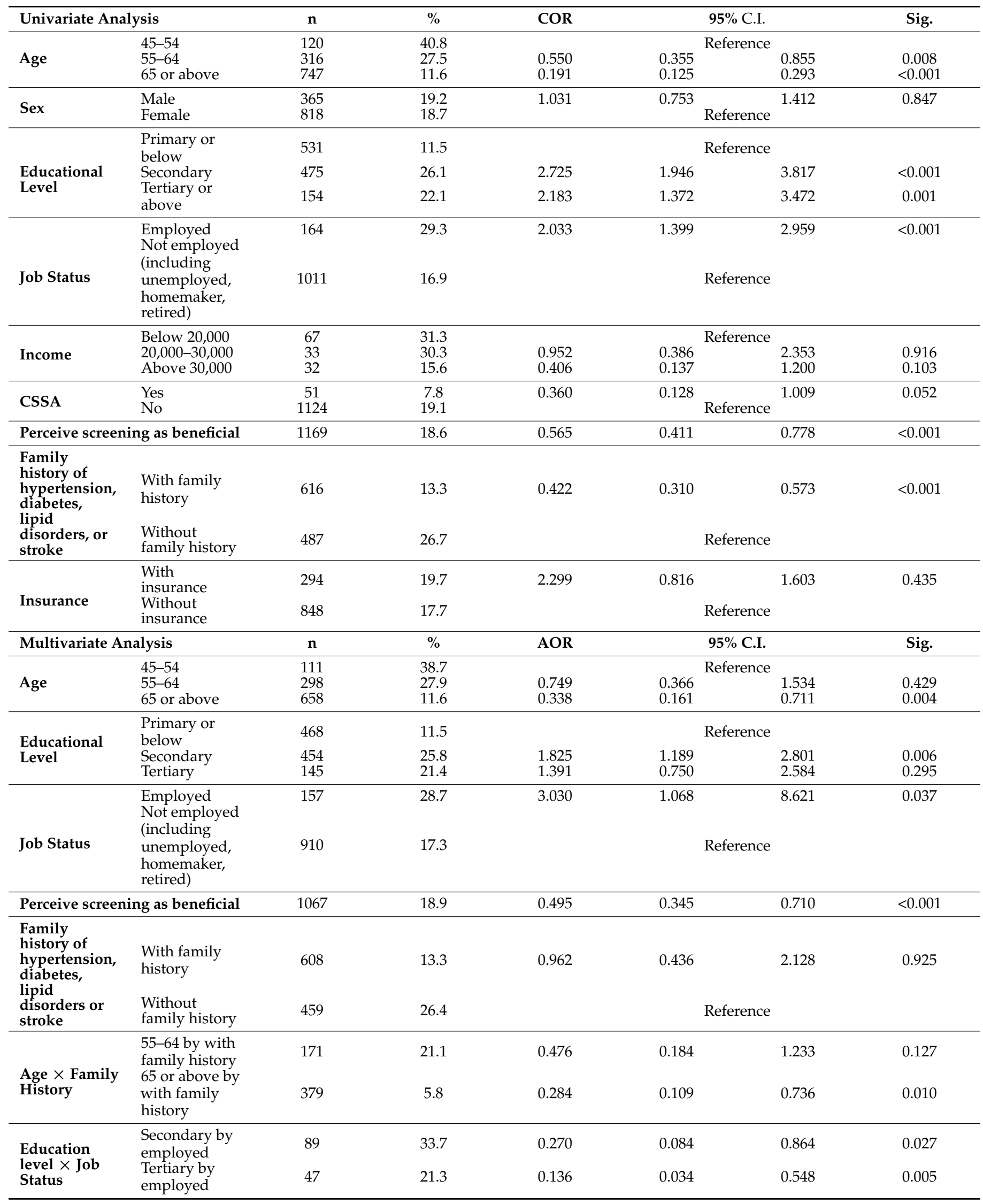


Table 3. Factors associated with not screening for at least two factors.

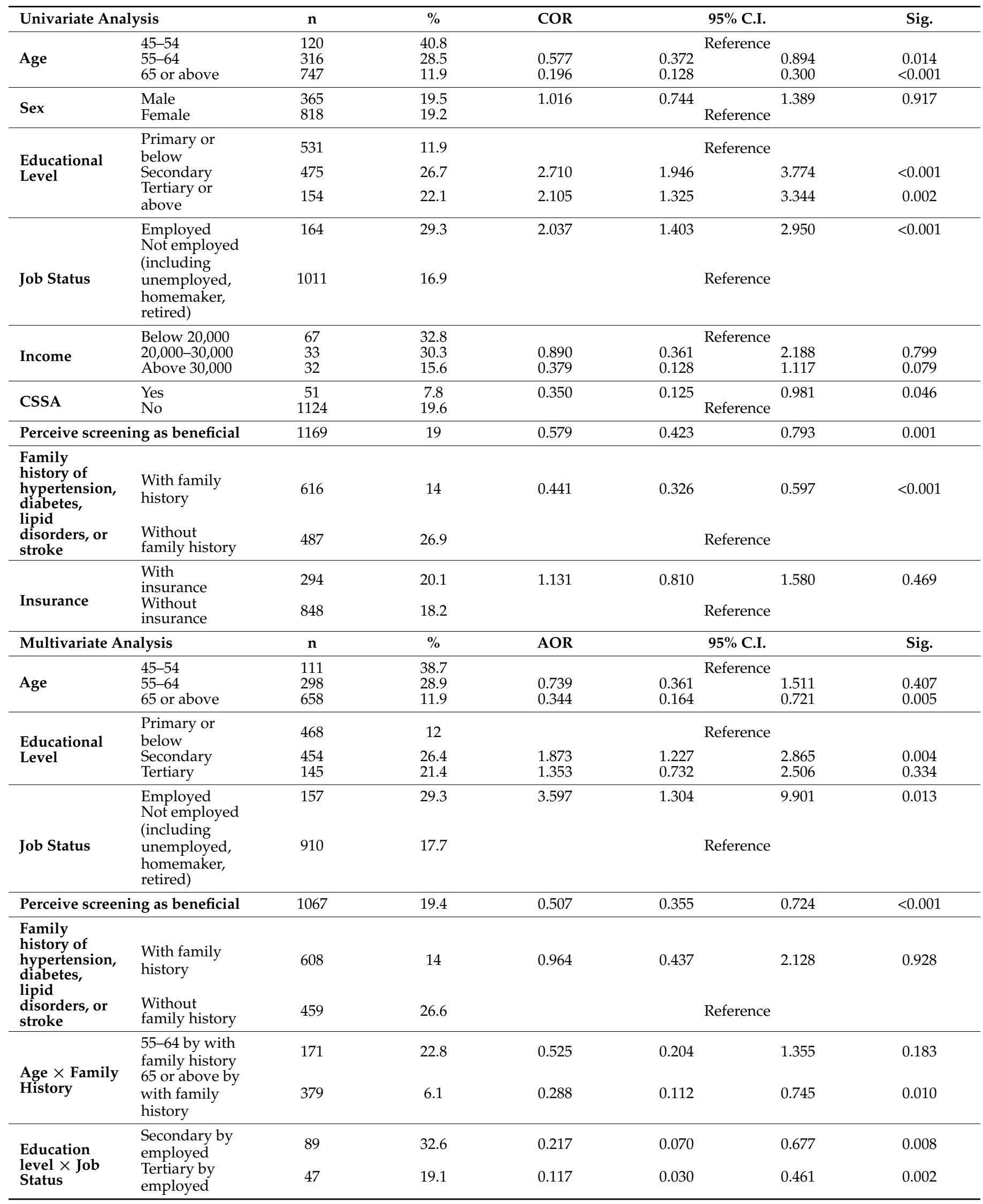


Table 4. Factors associated with not screening for all three factors.

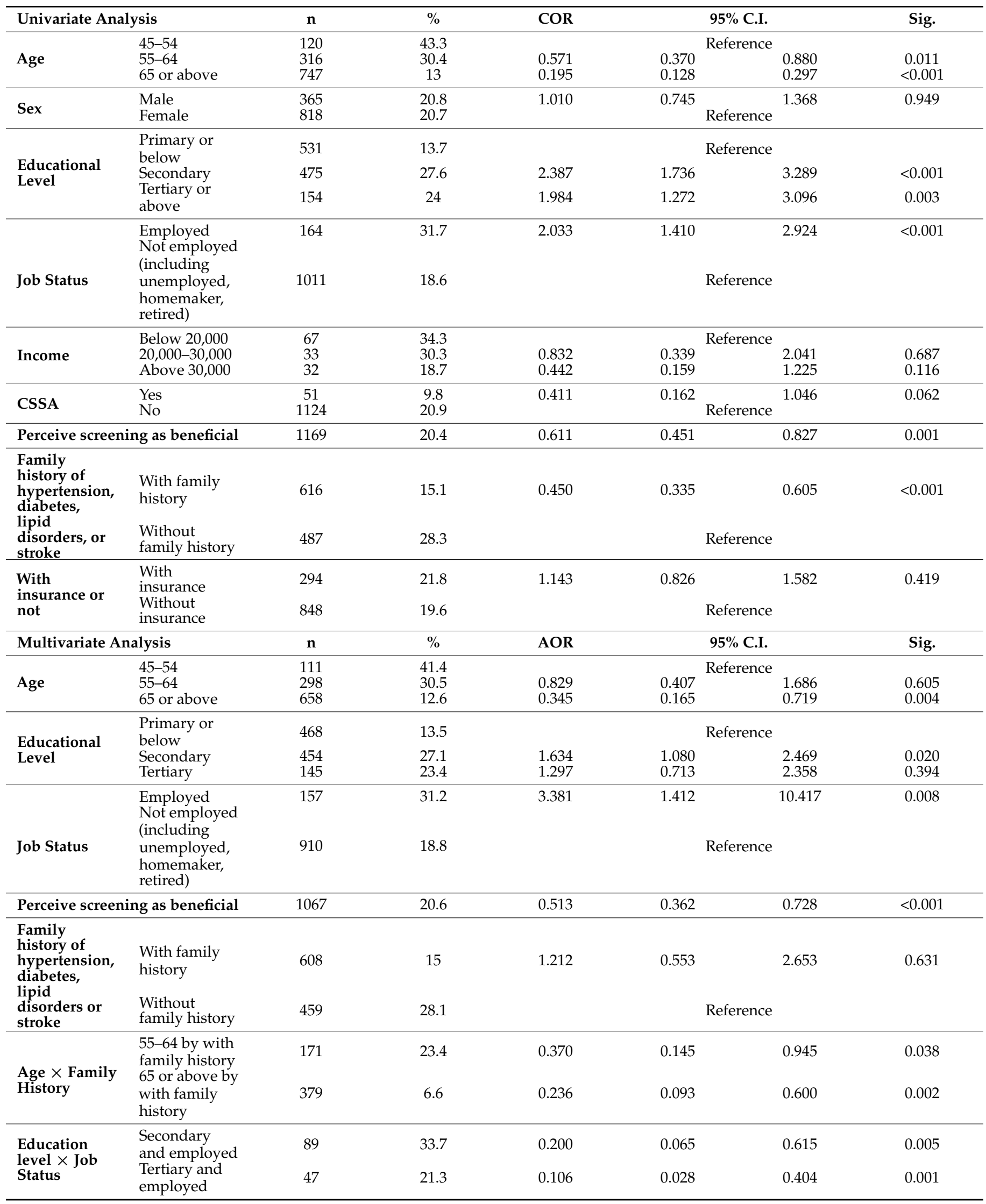


Table 5. Factors associated with unwillingness participate in voucher scheme for screening.

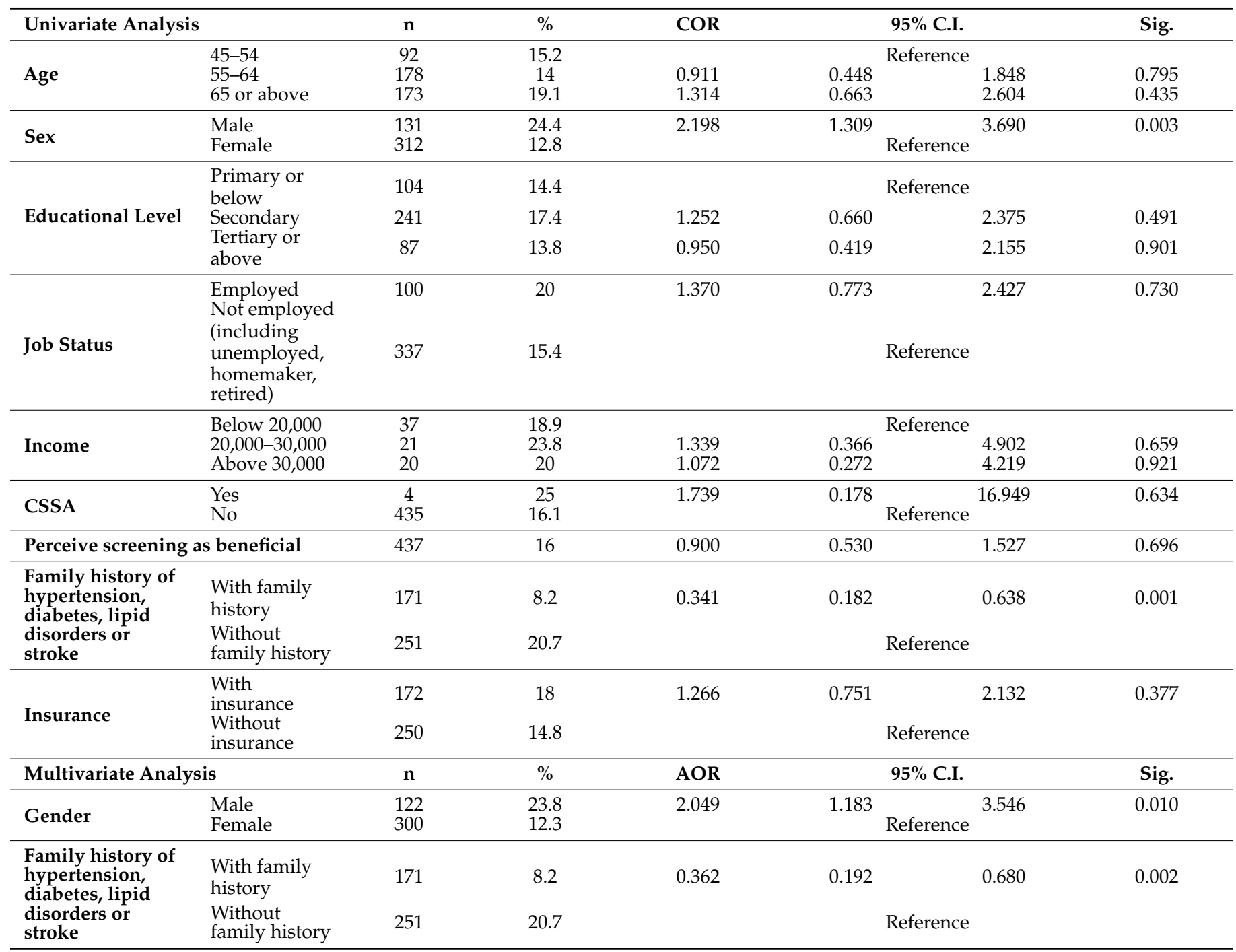


Table 6. Sex-specific willingness of participation in voucher scheme for screening.

\begin{tabular}{|c|c|c|c|c|c|c|c|}
\hline & & \multicolumn{2}{|c|}{ Male } & \multicolumn{2}{|c|}{ Female } & \multirow[b]{2}{*}{$x^{2}$} & \multirow[b]{2}{*}{$p$} \\
\hline & & $\mathbf{n}$ & $\%$ & $\mathbf{n}$ & $\%$ & & \\
\hline \multirow{2}{*}{$\begin{array}{l}\text { Willingness to } \\
\text { participate }\end{array}$} & Unwilling & 32 & 24.4 & 40 & 12.8 & & \\
\hline & Willing & 99 & 75.6 & 272 & 87.2 & 9.13 & 0.003 \\
\hline \multirow{3}{*}{ Age } & $45-54$ & 32 & 24.4 & 60 & 19.2 & & \\
\hline & $55-64$ & 48 & 36.6 & 130 & 41.7 & & \\
\hline & 65 or above & 51 & 38.9 & 122 & 39.1 & 1.78 & 0.411 \\
\hline \multirow{3}{*}{ Educational Level } & $\begin{array}{l}\text { Primary or } \\
\text { below }\end{array}$ & 23 & 18.1 & 81 & 26.6 & & \\
\hline & Secondary & 71 & 55.9 & 170 & 55.7 & & \\
\hline & $\begin{array}{l}\text { Tertiary or } \\
\text { above }\end{array}$ & 33 & 26.0 & 54 & 17.7 & 5.71 & 0.058 \\
\hline Job Status & $\begin{array}{l}\text { Employed } \\
\text { Not } \\
\text { employed } \\
\text { (including } \\
\text { unemployed, } \\
\text { homemaker, } \\
\text { retired) }\end{array}$ & 41 & 42.7 & 262 & 15.2 & 32.56 & $<0.001$ \\
\hline \multirow{3}{*}{ Income } & Below 20,000 & 9 & 23.7 & 28 & 70.0 & & \\
\hline & $\begin{array}{l}20,000- \\
30,000\end{array}$ & 16 & 42.1 & 5 & 12.5 & & \\
\hline & Above 30,000 & 13 & 34.2 & 7 & 17.5 & 17.28 & $<0.001$ \\
\hline \multirow{2}{*}{ CSSA } & Yes & 0 & 0.0 & 4 & 1.3 & & \\
\hline & No & 128 & 100.0 & 307 & 98.7 & na & 0.327 \\
\hline \multirow{2}{*}{$\begin{array}{l}\text { Family history of } \\
\text { hypertension, } \\
\text { diabetes, lipid } \\
\text { disorders or stroke }\end{array}$} & $\begin{array}{l}\text { With family } \\
\text { history }\end{array}$ & 40 & 32.8 & 131 & 43.7 & & \\
\hline & $\begin{array}{l}\text { Without } \\
\text { family } \\
\text { history }\end{array}$ & 82 & 67.2 & 169 & 56.3 & 4.26 & 0.039 \\
\hline \multirow{2}{*}{ Insurance } & $\begin{array}{l}\text { With } \\
\text { insurance }\end{array}$ & 60 & 48.4 & 112 & 37.6 & 4.26 & 0.039 \\
\hline & $\begin{array}{l}\text { Without } \\
\text { insurance }\end{array}$ & 64 & 51.6 & 186 & 62.4 & & \\
\hline
\end{tabular}

\section{Discussion}

From this telephone survey, we found that the overall rates of having received at least one type, two types, and all three types of screening test were $81.1 \%, 80.7 \%$, and $79.3 \%$, respectively, among those aged $\geq 45$. Consistent with this finding, the overall rate of willingness to join the voucher scheme for screening was $83.7 \%$. Several independent factors, including age, education level, employment status, social security assistance, and perception of the benefits of the screening and family history, were associated with not having received one, two, and all three types of screening test. With interaction effect being considered, younger individuals who did not have a family history of any of the three chronic diseases was associated with not having received screening for at least one medical condition. We also identified that independent factors of males and individuals who did not have family history of any of the three chronic diseases were associated with unwillingness to join a proposed screening programme. Since chronic disease is best managed at a younger age, it is important for us to identify the at-risk population and promote screening among them. However, the perceived risk of chronic diseases was usually lower in the young population. Therefore, the use of healthcare voucher and community education to increase awareness could be useful for promoting screening programmes of chronic diseases. 
Counterintuitively, in the multivariate analysis with variable interactions considered, we also found that employed persons and those with secondary education and above were also more likely not to have regular screening for the three medical conditions. One possible explanation could be they were busy and experienced time constraints in identifying and accessing structured screening programmes designed from established guidelines and perceived as benefit. Further studies may be needed to confirm this concomitantly. Consideration should be given by policy makers in providing better health promotion information on the recommended screening programmes of how and where these could be accessed.

This is the one of the few representative population-based studies in Hong Kong that examined the factors affecting participant's willingness to participate in hypertension, diabetes, and lipid disorder screening. It has a high response rate based on a random sampling strategy, and the survey instrument was validated by an expert panel. There are, nevertheless, several limitations that should be addressed. Firstly, this is a cross-sectional survey, and we could not establish a cause-and-effect relationship between the independent factors and the outcome. They could, however, be used in prediction of screening intention. Additionally, this survey examined risk associations in a Chinese population, and the generalizability of its findings to other settings should be approached cautiously. Finally, since the telephone survey relies on landline and there is a possibility of selection bias, although more than $91 \%$ of all Hong Kong residents have access to landlines [31].

Based on this study, it was found that male subjects without family history of chronic disease were less likely to receive hypertension, diabetes, and lipid disorder screening as compared to other individual factors. From this study, we found that males were less likely to join the voucher scheme in the future. Possible explanations include they were more likely to be employed and thus may have had limited time for the scheme for screening. Additionally, they tend to have higher income and health insurance, which may reduce the incentive effects of healthcare voucher. In addition, they have a lower perceived risk of cardiovascular diseases, as fewer male subjects had such a family history when compared with the females. Policymakers should allocate resources or raising awareness of the importance of screening for these disorders and provide health information on the recommended screening programmes and how and when they could be accessed by younger adults and men as well as those without any family history through promotional campaigns and health education. While it was observed that family history is associated with an increase in incidence of hypertension, diabetes, and lipid disorder, the overall incidence rate has also increased over the past decades with a shift towards younger patients, suggesting the need for early detection [39-42]. Having three types of screening is essential to detect and treat early and to identify potential high-risk individuals and provide proper recommendation for lowering their risk. This will not only benefit the patients but also benefit population health, lowering the demand on the healthcare system in the future and reducing the operation cost associated with these chronic diseases.

The results of the current study may inform how to use EHVCS to promote screening for cardiovascular risk factors among the older population in Hong Kong. However, the EHVCS alone may not be enough for promoting screening. Other strategies, including organised educational programmes and interactive reminders from physicians, could be useful for improving regular screening participation in the targeted group. It is recommended to disseminate more educational information regarding screening for cardiovascular designed to increase health awareness and reduce relevant barriers to promote their intention to join screening. To ensure a more extensive coverage and equity of access, organised educational programmes may be preferred, including health talks and seminars, newspaper advertisements, leaflets, or focus group interviews. A systematic reach of the high-risk population by invitations from general practice doctors could also help to promote the screening. For non-participants of screening programmes, sending additional reminders by healthcare professionals may be particularly effective. Interactive telephone reminders are believed to be more effective compared with short message services, WhatsApp, or 
emails. The above strategies could focus on younger individuals, subjects with higher educational levels, and those employed, as they were less likely to join in the screening for cardiovascular risk factors according to the current study.

\section{Conclusions}

In summary, this study has examined the factors independently associated with no participation in screening for hypertension, diabetes, and lipid disorders and their unwillingness to join the voucher scheme for screening. Our findings highlighted the significance of gender and family history on participation and acceptance of screening. The constructs and independent predictors identified provide evidence-based formulation and implementation of targeted screening strategies that enhance screening uptake and thus lower the impact of hypertension, diabetes, and lipid disorder on the health and demands on the healthcare system in the future.

Author Contributions: M.C.S.W., J.H., P.T. and E.-K.Y. participated in the conception of the research ideas, study design, interpretation of the findings, and writing of the first draft of the manuscript. J.H., C.-H.N., M.-S.T. and Q.S. retrieved information from the relevant databases and performed statistical analysis; M.C.S.W., J.H., P.T. and E.-K.Y. made critical revisions on the manuscripts and provided expert opinions on implications of the study findings. All authors have read and agreed to the published version of the manuscript.

Funding: This study was funded by Public Policy Research Funding Scheme (Project No.: 2020.A4.068.20B), The Government of the Hong Kong SAR.

Institutional Review Board Statement: This study was approved by the Survey and Behavioral Research Ethics Committee (Ref No. 143-19), Chinese University of Hong Kong.

Informed Consent Statement: Informed consent was obtained from all subjects involved in the study.

Data Availability Statement: The data are available upon reasonable request from the corresponding authors.

Acknowledgments: We acknowledge the general support of Kevin Law and Kristin Pun, The Jockey Club School of Public Health and Primary Care, Faculty of Medicine, Chinese University of Hong Kong in this project.

Conflicts of Interest: The authors declare no conflict of interest.

\section{References}

1. Bennett, J.E.; Stevens, G.A.; Mathers, C.D.; Bonita, R.; Rehm, J.; Kruk, M.E.; Riley, L.M.; Dain, K.; Kengne, A.P.; Kalipso Chalkidou, J.; et al. NCD Countdown 2030, worldwide trends in non-communicable disease mortality and progress towards Sustainable Development Goal target 3.4. Lancet 2018, 392, 1072-1088. [CrossRef]

2. Lehnert, T.; Heider, D.; Leicht, H.; Heinrich, S.; Corrieri, S.; Luppa, M.; Riedel-Heller, S.; König, H. Review: Health care utilization and costs of elderly persons with multiple chronic conditions. Med. Care Res. Rev. 2011, 68, 387-420. [CrossRef] [PubMed]

3. Sambamoorthi, U.; Tan, X.; Deb, A. Multiple chronic conditions and healthcare costs among adults. Expert Rev. Pharmacoecon. Outcomes Res. 2015, 15, 823-832. [CrossRef]

4. Grunfeld, E.; Manca, D.; Moineddin, R.; Thorpe, K.E.; Hoch, J.S.; Campbell-Scherer, D.; Meaney, C.; Rogers, J.; Beca, J.; Krueger, P.; et al. Improving chronic disease prevention and screening in primary care: Results of the BETTER pragmatic cluster randomized controlled trial. BMC Fam. Pract. 2013, 14, 175. [CrossRef]

5. Levy, N.; Dhatariya, K. Pre-operative optimisation of the surgical patient with diagnosed and undiagnosed diabetes: A practical review. Anaesthesia 2019, 74 (Suppl. 1), 58-66. [CrossRef] [PubMed]

6. Kaczorowski, J.; Chambers, L.W.; Dolovich, L.; Paterson, J.M.; Karawalajtys, K.; Gierman, T.; Farrell, B.; McDonough, B.; Thabane, $\mathrm{L}$; $\mathrm{Tu}, \mathrm{K}$.; et al. Improving cardiovascular health at population level: 39 community cluster randomised trial of Cardiovascular Health Awareness Program (CHAP). BMJ 2011, 342, d442. [CrossRef]

7. Centre for Health Protection, Department of Health, Hong Kong SAR Government. Report of Population Health Survey 2014/15 2017. Available online: https://www.chp.gov.hk/files/pdf/dh_phs_2014_15_full_report_eng.pdf (accessed on 1 August 2019).

8. Chung, R.Y.; Tin, K.Y.; Cowling, B.J.; Chan, K.P.; Chan, W.M.; Lo, S.V.; Leung, G.M. Long-term care cost drivers and expenditure projection to 2036 in Hong Kong. BMC Health Serv. Res 2009, 9, 172. [CrossRef] [PubMed] 
9. Mahikul, W.; White, L.J.; Poovorawan, K.; Soonthornworasiri, N.; Sukontamarn, P.; Chanthavilay, P.; Pan-ngum, W.; Medley, G.F. A Population Dynamic Model to Assess the Diabetes Screening and Reporting Programs and Project the Burden of Undiagnosed Diabetes in Thailand. Int. J. Environ. Res. Public Health 2019, 16, 2207. [CrossRef]

10. Hill, P.L.; Roberts, B.W. The role of adherence in the relationship between conscientiousness and perceived health. Health Psychol 2011, 30, 797-804. [CrossRef]

11. Department of Health, Hong Kong SAR Government. Health Facts of Hong Kong 2020. 2020. Available online: https: //www.dh.gov.hk/english/statistics/statistics_hs/files/2020.pdf (accessed on 22 July 2021).

12. Centre for Health Protection, Department of Health, Hong Kong SAR Government. Non-Communicable Diseases and Healthy Living-Hypertension 2019. Available online: https://www.chp.gov.hk/en/healthtopics/content/25/35390.html (accessed on 1 August 2019).

13. Centre for Health Protection, Department of Health, Hong Kong SAR Government. Non-Communicable Disease and Healthy Living_Diabetes Mellitus 2017. Available online: https:/ /www.chp.gov.hk/en/healthtopics/content/25/59.html (accessed on 1 August 2019).

14. Quan, J.; Zhang, H.; Pang, D.; Chen, B.K.; Johnston, J.M.; Jian, W.; Lau, Z.Y.; Iizuka, T.; Leung, G.M.; Fang, H.; et al. Avoidable hospital admissions from diabetes complications in Japan, Singapore, Hong Kong, and communities outside Beijing. Health Aff. 2017, 36, 1896-1903. [CrossRef]

15. Quan, J.; Li, T.K.; Pang, H.; Choi, C.H.; Siu, S.C.; Tang, S.Y.; Wat, N.M.; Woo, J.; Johnston, J.M.; Leung, G.M. Diabetes incidence and prevalence in Hong Kong, China during 2006-2014. Diabet. Med. 2017, 34, 902-908. [CrossRef] [PubMed]

16. Preventive Services Task Force. Screening for type 2 diabetes mellitus in adults: Recommendations and rational. Ann. Intern. Med. 2003, 138, 21.

17. National, C.E. Third report of the National Cholesterol Education Program (NCEP) expert panel on detection, evaluation, and treatment of high blood cholesterol in adults (Adult Treatment Panel III) final report. Circulation 2002, 106, 3143.

18. Berg, A.O. Screening adults for lipid disorders: Recommendations and rationale. Am. J. Prev. Med. 2001, 20, 73-76.

19. Rifas-Shiman, S.L.; Forman, J.P.; Lane, K.; Caspard, H.; Gillman, M.W. Diabetes and lipid screening among patients in primary care: A cohort study. BMC Health Serv. Res. 2008, 8, 25. [CrossRef] [PubMed]

20. Penn, L.; Rodrigues, A.; Haste, A.; Marques, M.M.; Budig, K.; Sainsbury, K.; Bell, R.; Araújo-Soares, V.; White, M.; Summerbell, C.; et al. NHS Diabetes Prevention Programme in England: Formative evaluation of the programme in early phase implementation. BMJ Open 2018, 8, e019467. [CrossRef] [PubMed]

21. Krass, I.; Carter, R.; Mitchell, B.; Mohebbi, M.; Shih, S.T.; Trinder, P.; Versace, V.L.; Wilson, F.; Mc Namara, K. Pharmacy Diabetes Screening Trial: Protocol for a pragmatic cluster-randomised controlled trial to compare three screening methods for undiagnosed type 2 diabetes in Australian community pharmacy. BMJ Open 2017, 7, e017725. [CrossRef] [PubMed]

22. Ministry of Health, Health Hub. Screen for Life 2019. Available online: https://www.healthhub.sg/programmes/61/Screen_for_ Life (accessed on 1 August 2019).

23. Minister of Health, Singapore. Take-up Rate of Screen for Life Programme. 5 April 2021. Available online: https://www.moh. gov.sg/news-highlights/details/take-up-rate-of-screen-for-life-programme (accessed on 28 July 2021).

24. Ensor, T. Consumer-led demand side financing in health and education and its relevance for low and middle income countries. Int. J. Health Plan. Manag. 2004, 19, 267-285. [CrossRef]

25. Kingkaew, P.; Werayingyong, P.; Aye, S.S.; Tin, N.; Singh, A.; Myint, P.; Teerawattananon, Y. An ex-ante economic evaluation of the Maternal and Child Health Voucher Scheme as a decision-making tool in Myanmar. Health Policy Plan. 2015, 31, 482-492.

26. Sandiford, P.; Gorter, A.; Salvetto, M.; Rojas, Z. A Guide to Competitive Vouchers in Health; World Bank: Washington, DC, USA, 2004.

27. Brody, C.M.; Bellows, N.; Campbell, M.; Potts, M. The impact of vouchers on the use and quality of health care in developing countries: A systematic review. Glob. Public Health 2013, 8, 363-388.

28. Grainger, C.; Gorter, A.; Okal, J.; Bellows, B. Lessons from sexual and reproductive health voucher program design and function: A comprehensive review. Int. J. Equity Health 2014, 13, 33. [CrossRef]

29. Hunter, B.M.; Harrison, S.; Portela, A.; Bick, D. The effects of cash transfers and vouchers on the use and quality of maternity care services: A systematic review. PLoS ONE 2017, 12, e0173068. [CrossRef]

30. Sicsic, J.; Franc, C. Obstacles to the uptake of breast, cervical, and colorectal cancer screenings: What remains to be achieved by French national programmes? BMC Health Serv. Res. 2014, 14, 465. [CrossRef] [PubMed]

31. Huang, J.; Choi, P.; Pang, T.W.Y.; Chen, X.; Wang, J.; Ding, H.; Jin, Y.; Zheng, Z.J.; Wong, M.C.S. Factors associated with participation in colorectal cancer screening: A population-based study of 7200 individuals. Eur. J. Cancer Care 2021, 30, e13369. [CrossRef] [PubMed]

32. Yam, C.H.K.; Wong, E.L.Y.; Fung, V.L.H.; Griffiths, S.M.; Yeoh, E.-K. What is the long term impact of voucher scheme on primary care? Findings from a repeated cross sectional study using propensity score matching. BMC Health Serv. Res. 2019, 19, 875. [CrossRef] [PubMed]

33. HKSAR. The Elderly Health Care Voucher Scheme. Available online: https://www.hcv.gov.hk/eng/pub_sz_bg.htm (accessed on 10 July 2021).

34. Legislative Council, Panel on Health Services. Paper on the Elderly Health Care Voucher Scheme Prepared by the Legislative Council Secretariat (Background Brief) Papers, Healthcare Services for the Elderly: CB(2)235/15-16(09). 2015. Available online: https:/ / www.legco.gov.hk/yr15-16/english/panels/hs/papers/hs20151116cb2-235-9-e.pdf (accessed on 28 July 2021). 
35. Schoeb, V. Healthcare Service in Hong Kong and its Challenges: The Role of Health Professionals within a Social Model of Health. China Perspect. 2016, 2016, 51-58. [CrossRef]

36. Census and Statistical Department 2016 Population by-Census: Summary Results. 2016. Available online: https://www. bycensus2016.gov.hk/data/16bc-summary-results.pdf (accessed on 28 July 2021).

37. Rosenstock, I.M.; Strecher, V.J.; Becker, M.H. Social learning theory and the Health Belief Model. Health Educ. Q 1988, 15, 175-183. [CrossRef]

38. Gambino, J.G.; do Nascimento Silva, P.L. Chapter 16-Sampling and Estimation in Household Surveys. In Handbook of Statistics; Rao, C.R., Ed.; Elsevier: Amsterdam, The Netherlands, 2009; Volume 29, pp. 407-439.

39. Luk, A.O.Y.; Ke, C.; Lau, E.S.H.; Wu, H.; Goggins, W.; Ma, R.C.W.; Chow, E.; Kong, A.P.S.; So, W.Y.; Chan, J.C.N. Secular trends in incidence of type 1 and type 2 diabetes in Hong Kong: A retrospective cohort study. PLoS Med. 2020, 17, e1003052. [CrossRef]

40. Wong, M.C.S.; Wang, H.H.X.; Leung, M.C.M.; Tsang, C.S.H.; Lo, S.V.; Griffiths, S.M. The rising prevalence of self-reported hypertension among Chinese subjects: A population-based study from 121895 household interviews. QJM Int. J. Med. 2015, 108, 9-17. [CrossRef] [PubMed]

41. Lee, V.W.; Law, S.L. Ten-year cardiovascular risk in the general public of Hong Kong. Heart Asia 2011, 3, 111-114.

42. Wong, M.C.; Huang, J.; Pang, T.W.; Lok, V.; Chen, X.; Choi, P.; Leung, C.; Wang, H.H.X.; Lao, X.Q.; Zheng, Z.J. Worldwide incidenceand prevalence of metabolic syndrome: A systematic review and meta-analysis of 14.6 million individuals. Gastroenterology 2020, 158, S-1003. [CrossRef] 